\title{
The Methods and Applications of Creative Teaching in Design
}

\author{
*Ya-Kuan Chou; **Ruey-Sen Chiu; ***Ping-Yeh Li; ****Yun-Ju Chen \\ * China University of Technology; No. 56, Sec. 3, Xinglong Rd., Wunshan District Taipei City 116, Taiwan (R.O.C.); \\ miaululumi@yahoo.com.tw \\ ** China University of Technology; No. 56, Sec. 3, Xinglong Rd., Wunshan District Taipei City 116, Taiwan (R.O.C.) \\ *** (Corresponding Author) China University of Technology; No. 56, Sec. 3, Xinglong Rd., Wunshan District Taipei City 116, \\ Taiwan (R.O.C.); pingyehli@gmail.com \\ **** China University of Technology; No. 56, Sec. 3, Xinglong Rd., Wunshan District Taipei City 116, Taiwan (R.O.C.)
}

\begin{abstract}
The purpose of this study is to explore the creative teaching methods in design education. This study conducts literature review on the related fields, invites 7 design teachers to join an expert interview, and use qualitative analysis software ATLAS.ti to analyze their creative learning methods in design.

This study found that teacher can use free discussion, number restriction, theoretical-based guidance and stimulus to increase the ability of fluency; Use teacher guidance, subject restriction and assistance induction to increase the ability of flexibility; Use teacher suggest, students discuss, and market benefits analysis to increase the ability of Originality; Use principle of demonstration, product planning, user preferences and challenge students to increase the ability of the elaboration to increase students' creativity in creative design course.
\end{abstract}

Key words: Creativity, Creativity Teaching, Design Education

\section{Introduction}

Traditional Taiwan education prefers narrative education model. Teachers duplicate the individual's professional abilities to enable students to acquire knowledge based on the correct answers, but this method is lack of ability to develop students' critical thinking skills. Pin Zhang, Lin (1990) once pointed out that innovative thinking is the main focus of creative teaching in design. However, creativity is not easy to teach, and difficult to learn as well. Currently, there are no regulated creative teaching methods in Taiwan design education, yet. Teacher could only go through variety of ways to stimulate ones' imaginations.

Innovation is our innate abilities, and everyone is born with innovation afflatus. The British Encyclopedia mentioned that, innovation is the ability to actuate new things in life; Webster's Dictionary defines innovation as an ability of creating or making originality rather than plagiarism. In other words, innovation is the ability to create invention through originality, uniqueness and novelty (Fen Ming, Li, 2008) Innovation is to break through the old ways or things, create new contexts, and has three characteristic: novelty, value, and able to bring surprises. (Shi Zhong, Zhang, 2002; Si Hua, Wu, 1996)

Innovative thinking is an advance form of human thinking, which can be used to understand the nature of things and their intrinsic relations, and produced innovative thinking results. Innovative thinking is also often used in problem solving, but not through the learning and application of existing knowledge, it is through creativity, by using existing knowledge or applying new methods on problem solving instead. (Guan Rong, Jing, 2005).

The purpose of creativity teaching is to develop students' creativities, motivate students to create, encourage them to perform creation that will enhance the talent of creation. (Wright, 1990). Davis (1986) pointed out that creativity teaching mainly enabled students to develop the sense of creating and good creating attitude, to let students be more aware of the theme of creativity, to devote students to creative activities, to enable students to apply creative solutions and enhance students' creativity personalities, to help students to learn to create thinking skills and to enhance students' creative thinking abilities through practices.

In order to understand the creative teaching methods used by the design education, this research study uses a semi-structured questionnaire to interview seven teachers with creativity teaching experience in design education, along with the ATLAS.ti software to understand the current creative teaching methods, as the reference for the teachers of the creativity teaching methods.

\section{Research Design}

A. Research Methodology

1. Content Analysis, also known as document analysis or information analysis, is mainly used to explain a phenomenon of a specific time or sate, or the development of the phenomenon within certain period of time. (Wenke, Wang, 2003). In this study, a meta-analysis of the literature related to creativity teaching is taken as reference for the preparation of in-depth interview questions.

2. Interview is one of the method widely used in social science for data collection. Interviewers obtain the opinions of the respondents on a specific issue, with the aim of collecting research information. In this research, experts related to creativity teaching are invited to discuss the problems experienced by the teachers during the process of creativity teaching in design education, by sharing the experiences and exchanging opinions through discussions to understand the overview of creativity teaching in design education.

3. Grounded Theory is the systematic generation of theory from data conceptualization. The Grounded Theory used in this study mainly focuses on the data collected from the interviews with experts and is analyzed by the ATLAS.ti software to summarize the current teachers' behaviors toward creative teaching. 


\section{B. Research Sample}

In order to understand the insights of creativity teaching from the teachers of design education, this research invited seven teachers from design education industry which served in tertiary institutions that are based in north, central and southern of Taiwan. These teachers had a certain years of experiences in design education. The interview is done one by one, and about 30-60 minutes each, the entire process is recorded and convert the interview content into a verbatim draft, as the base of grounded theory analysis.

\section{Results and Analysis}

Creativity is continuous. During the process of creativity development, there will be various kind of creativities going on The creativity forces mentioned by Torrance (1996) are divided into four categories, fluency, flexibility, originality and elaboration. To assist the development of creative continuity (Figure 1), this study established the semi-structured interviews based on this, and interview to understand how teachers in current institutions can guide students to exert these four creativities. The results are as follow:

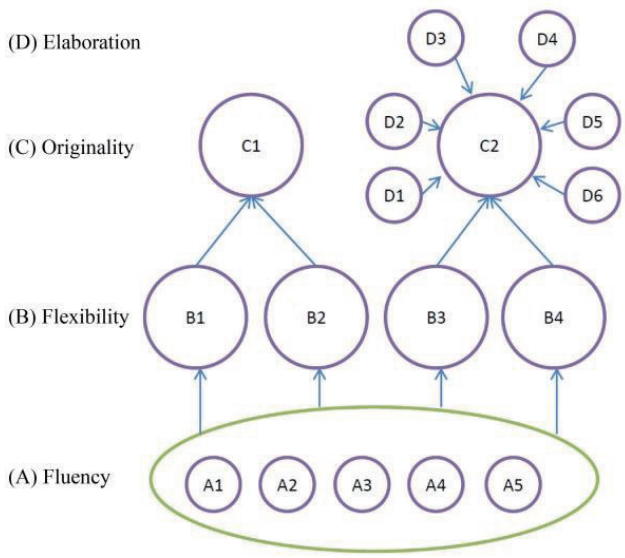

Figure 1. Creativity Development Concept Illustration

\section{A. Fluency}

According to Torrance (1996), fluency refers to the ability to generate a large number of ideas and summarize all relevant reactions over a certain period of time. The higher the number of responses, the higher the fluency. Therefore, fluency refers to the divergent of the thinking ability in the process of creative thinking. According to the results of the interviews, there are mainly four ways that teachers in design education are using to provide ideas: free play, number of restrictions, theoretical basis, and stimuli. The contents are as follows:

1. Free Play: provide themes or keywords to the student, and direct student to creative thinking.

2. Number of Restrictions: The number of restrictions consists of two ways, the first only allow students to propose a small amount of ideas, so that students can be cautious before making ideas; which result in a more valuable and practical implementation of the idea. The second is to be specify a certain amount of ideas required to be produced to help students practice their thinking over a fixed period of time.

3. Theoretical Basis; Before students go through creative thinking process, firstly explain the theory and summarized the key points, then give an example to the students to listen to and conduct practical analysis so that the students have a profound understanding of the theory and aware of how the existing enterprise implement this theory, so that the students can put into practical/

4. Stimuli: To look for pictures or items related to the topic, and search for creative contents from these items.

\section{B. Flexibility}

According to Torrance (1996), creativity is the power of being flexible, able to summarize all types of reactions in a certain period of time, the higher the variety of reactions, the more flexible it is. Flexibility mentioned in this study referring to convergence of creative thinking ability. Based on the interview results, there are three ways that are often used by the teachers in the current design education: teacher guidance, subject limitation, and classification assistance, and the contents are as follows:

1. Teacher Guidance: to discuss directly with the teachers, and teachers help students to clarify the advantages and disadvantages between ideas based on knowledge and experiences of the teachers and allowed students to practice judgments and perform screenings to stimulate students to generate further ideas.

2. Subject Limitation: To limit topics and settings such as qualifying materials, colors, scenarios, ethnic groups, occasions or specific conditions to converge students' ideas.

3. Classification Assistance: ask students to review the ideas and classify similar ideas into new category.

\section{Originality}

According to Torrance (1996), originality means the combinations of rare reaction over a certain period of time. The more the rare reactions are, the higher the originality. Therefore, the creative power mentioned in this research refers to the ability to produce valuable ideas through the process of creative thinking. Based on the interviews results, there are three different ways that is often used by the teachers in helping the students to generate valuable ideas, teacher's suggestions, discussions among students and market effects. The contents of the interviews are as follows:

1. Teacher's suggestions: Based on the experiences of the teachers, through the data analysis compiled by the students, along with current social conditions and future development trends, a comprehensive analysis is made and students are informed on the demand in the market in order to produce valuable ideas.

2. Discussions among students: Based on students' experiences, after students have discussed and share their opinions with each other, they can make preliminary judgments after consensus has been reached by all. However, students are usually lack of experiences and knowledge. Therefore, teachers' suggestions are usually 


\section{Recent Developments on Information and Communication Technology (ICT) Engineering- Meen, Yang E Zhao \\ ISBN: 978-981-14-2136-5}

creating a big impact on students' thoughts.

3. Market Effects: From the perspective of market, the issue of resource allocation need to be considered. When producers have limited resources, they will seek for the best combinations to achieve highest benefits with limited resources.

\section{Elaboration}

According to Torrance (1996), Elaboration is the sum of additional details within a certain period of time. The more the details are, the higher the elaboration is. Elaboration mentioned in this interview is referring to the ability to develop the product in details during the creative thinking process. Based on the interview results, there are four ways that the teachers often used to assist students in developing product details, principle of demonstration, product planning, user preference, and challenges toward students. The contents are described as follows:

1. Principle of Demonstration: Based on their own knowledge and experience, teachers tell students how to deal with the details and help students to structure the selection of the issues, so that students can have further direction on making choices based on the right judgments.

2. Product Planning: Write down the product plan, and list the principles and details that are important. For instance, the product features, functions, materials, color, processing methods and other factors that is used in the discussion to obtain preliminary product characteristics.

3. User preferences: To understand user preferences. For example, if the target is targeted at specific ethnic group, a one-by-one review is to be conducted based on gender needs, psychological preferences, physical characteristics, and living habits of the ethnic group, to understand what is lacking in the current idea, in order to improve them.

4. Challenges toward students: As students develop details, teachers question students on the yet to developed ideas, so that it allowed students to think repeatedly before answering those questions, in order to create a more complete idea of creativity.

\section{E. Comprehensive Guide}

In fact, in actual operation of creativity teaching, teachers in the design education industry do not particularly teach those abilities used in creative thinking. Therefore, this research integrated the creative methods proposed by the teachers and concluded the five most commonly used comprehensive guide, as follows:

1. Free guidance: Teachers do not teach specific methods. Instead, when teachers asked questions, students should take own initiatives to experience, to feel their senses, to explore the problems and to innovate. Students should allowed to experience failure, accept failure, and overcome the failure, in order to understand what is lacking in the original ideas to make improvements, so they could complete the creative works.

2. Guidance of creative methods: There are quite a few existing creative methods, each of which has its own advantages and disadvantages. However, with the use of creative methods, students can use logical thinking to analyze and summarize, which resulting in ideas with depth and breadth.

3. Stimulus guidance: To provide students tips by giving direction, items, or conditions, so that students can revert with creative ideas.

4. Cross-field guidance: Creativity teaching coached by different teacher from various faculties will lead students to look at the same thing through different aspects and integrate the cross-field knowledge to create creative ideas.

\section{Conclusion}

In order to understand the current creative teaching methods in design education industry, this research study based on interviews with seven teachers in design faculty and applied content analysis method, interview method and grounded theory. The results shows that current teachers often teach students creativity based on the methods below:

1. Fluency: Students can produce a lot of ideas by means of free play, quantity limitations, theoretical basis and stimuli.

2. Flexibility: Through these three ways: teachers' guidance, subject limitations, classifications assistance, it helped students to perform classifications and summarizations.

3. Creativity: Teachers' advices, class discussions, market effects help students to produce valuable views.

4. Elaboration: Principle of demonstration, product planning, user preferences, challenges toward students, are the four ways to help students generate additional details of the product.

5. Comprehensive Guide: Teachers of the design education industry often used free guidance, experience guidance, guidance of creative methods, stimulus guidance, and cross-field guidance to help students to develop comprehensive creative thinking.

\section{References}

[1] Fen-Ming Lee and Yao-Hui Zhuang, Creative Thinking, 2008, New Taipei City, New Wun Ching Developmental Publishing.

[2] Davis, G.A., Creativity is forever (2nd ed.), 1986, Dubuque, IA: Kendall/Hunt.

[3] Guan-Rong Jing, creatology: Theory and Application, 2005, New Taipei City, New Wun Ching Developmental Publishing.

[4] Pin-Chang LIN, Basic Design Education, 1990, Taipei, Artist.

[5] Syh-Jong Jang, Creative Teaching: application and example, 2002, Taipei, Pro-ed Publishing.

[6] Szu-Hua Wu, Create High-Quality Enterprises with Innovation, 2000, Taipei, EMBA World Exeecutivee's Digest.

[7] Wen-Ke Wang, Curriculum and Teaching Methodology, 2003, Taipei, Wu-Nan Book.

[8] Wright, C., \& Fesler, L. L., Nurturing creative potentials: A model early childhood program. In C. W. Taylor (Ed.), Expanding awareness of creative potentials worldwide, 1990, Salt Lake, UT: Braib Talent-powers, pp. 138-142. 
Recent Developments on Information and

Communication Technology (ICT) Engineering- Meen, Yang \& Zhao ISBN: 978-981-14-2136-5 